\title{
An Experimental Study of Russian and Swedish Value Systems
}

\author{
V. Shabes, G. Bostedt, E. Troshchenkova, \\ L. Ivarsson, U. Damber, T. Potapova
}

\begin{abstract}
The purpose of this study was to develop a method comparing Russian and Swedish value systems with the overarching aim to increase the understanding in intercultural communication. Value systems, as organized systems of nationally specific social concepts, are viewed as part of the cognitive, mental representations determining the behaviour of both individuals and communities. In comparative studies of value systems concepts in the national languages are often translated into English. Our Russian-Swedish project has indicated that similar national concepts, when translated into English, expose significant differences in their connotations. For example, when comparing the Swedish and Russian translations of 'security', much of the nationally specific contents are lost, thus, making data invalid. To overcome this problem, methods were developed to obtain comparable data, by use of experimental design, employing Russian and Swedish university students as informants. In our presentation we will explicate how simple value concepts coinciding for the two cultures were obtained and how differences in similar concepts were identified. We will describe the overall structure of the multilayer value systems of both countries, where similarities and differences related to gender and ethnicity, are made visible. The methodology, results and presumptive usages of these methods will be presented.
\end{abstract}

Key Words: Values, system, culture, methodology, comparison, similarity, difference, graded standard.

$* * * * *$

\section{Introduction}

This article focuses on values that are understood as components of social and mental representations regulating human behaviour in a society ${ }^{1}$. Values, thereby, serve as guiding principles in people's life $^{2}$. There are different value types ${ }^{3}$, encompassing societal and individual distinctions, enabling us to understand moral foundations and principles for everyday actions taken by the citizens.

In this article we present a comparative study of values in Russia and Sweden. The aims for this article are twofold; firstly, to present and 
discuss a methodological approach to comparative analysis in the area of value studies, and secondly, to present and analyse Russian and Swedish young people's perspectives on basic values in the two countries. During the last two decades Russia has experienced a societal transformation from a totalitarian society towards democracy with a novel value system in development ${ }^{4}$. Sweden, on the other hand, has history of a 'third way' (the Swedish model), in terms of over time relative stable societal values, democracy and mixed economy, thus, making comparisons between the two countries intriguing to analyse ${ }^{5}$.

\section{Methodology}

This comparative study was carried out in several steps that will be chronologically described below.

In the first phase of the study value nominations were selected for further analysis and comparison. 100 male and 100 female respondents from each country (students from 19 to 30 ) were given a questionnaire, including questions on background information, such as place of birth, parent's educational level, personal religious beliefs, and age, as we assumed that geographical, socio-economical and educational differences may influence the formation of value systems of the respondents. The respondents were asked to "Write down all values that you find important", marking the value they mentioned as "important for me", "important for the society" or "both". The age interval was chosen due to the important formative function the years between adolescence and adulthood has in the lives of young adults. There were no limits as to how many or what kind of values the respondents could write.

As a result we obtained a total of 156 values for Russians and 77 for Swedes (closely related ones, for e.g. family, parents, relatives, were clustered). The respondents mentioned values of different levels: some of the value nominations being more complex and general, including a number of simple concepts ${ }^{6}$.

Therefore, to make comparisons of value nominations possible we needed to know the components of complex values, so we conducted the second phase of the study. 78 Russian and 62 Swedish respondents got a list of 11 and 10 values, correspondingly, that we considered complex on the basis of the first phase of the study.

Analysis of the obtained components for complex values suggested dividing them, when possible, into ones with positive/neutral or negative connotations, which was important for further cultural comparisons.

In the third phase of the study a joint list of 31 values was created in order to make direct ranking possible by creating a "graded standard"7. The list was given to 50 Swedish women, 38 Swedish men, 57 Russian women and 46 Russian men who were asked to arrange value nominations in order 
from the most important to the least important, according to their personal preference. By calculating the means for each value we could determine its relative position within the graded scale, thus revealing the degree of its importance within the system.

To determine the degree of similarity/difference between nationalities, as well as genders, we referred to the theory of fuzzy sets, i.e. a theory of graded concepts ${ }^{8}$. To count the similarity/difference index (Ks), we used a formula by Sørensen 9 ,

$$
\mathrm{Ks}=\frac{2 \mathrm{C}}{-\mathrm{A}+\mathrm{B}}
$$

where, in our case, A equals the total number of putting the particular value in all places of the graded scale by, for example, the Russians, B by the Swedes, and $\mathrm{C}$ the total of overlapping answers in each place of the graded scale. Ks equalling 0 indicates absence of similarity and 1 indicates maximum similarity.

\section{Results}

The data collected in the first phase of the study generated a number of interesting comparisons between the two countries, as well as, between genders both within and between the two countries. Examples of these similarities and differences are displayed in table 1. For instance, betweenthe-cultures comparison shows difference in such values as Democracy, Culture and similarity in Material wealth, Family, Education and Health.

The four most frequently mentioned values by both genders in both countries were Material wealth, Family, Education, and Health. In the fifth place the Russian respondents mentioned Love, whereas Swedes mentioned Democracy.

Table 1 Value nomination presented in total and divided into countries as well as divided into answers given by males and females. Russia $n=1775$, Sweden $n=1066$. Absolute numbers and percent

\begin{tabular}{lllllllll} 
& \multicolumn{1}{l}{ Total } & \multicolumn{5}{l}{ Number of entries } \\
\cline { 2 - 9 } & \multicolumn{2}{l}{ Absolute no. } & \multicolumn{2}{c}{ Percent } & \multicolumn{2}{c}{ Females } & \multicolumn{2}{c}{ Males } \\
\cline { 2 - 9 } Value nomination & Russia & Sweden & Russia & Sweden & Russia & Sweden & Russia & Sweden \\
\hline Material wealth & 123 & 89 & 6.9 & 8.3 & 5.7 & 6.2 & 8.9 & 11.1 \\
Family & 112 & 82 & 6.3 & 7.7 & 6.0 & 6.4 & 6.7 & 9.3 \\
Education & 89 & 81 & 5.0 & 7.6 & 5.7 & 7.7 & 3.9 & 7.4 \\
Love & 80 & 27 & 4.5 & 2.5 & 5.0 & 2.8 & 3.7 & 2.3
\end{tabular}




\begin{tabular}{lllllllll}
\hline Friendship & 64 & 65 & 3.6 & 6.1 & 4.3 & 4.3 & 2.5 & 8.2 \\
Culture & 54 & 7 & 3.0 & 0.7 & 2.4 & 0.5 & 4.1 & 0.8 \\
Freedom & 49 & 53 & 2.8 & 5.0 & 1.2 & 6.4 & 5.3 & 3.2 \\
Health & 82 & 104 & 4.6 & 9.8 & 4.9 & 7.7 & 4.1 & 12.2 \\
Democracy & 1 & 68 & 0.0 & 6.4 & 0.0 & 10.0 & 0.1 & 2.1 \\
Job & 33 & 56 & 1.9 & 5.3 & 1.4 & 2.8 & 2.6 & 8.2 \\
Security & 4 & 57 & 0.2 & 5.3 & 0.2 & 6.5 & 0.3 & 3.9 \\
Care for citizens & 32 & 49 & 1.8 & 4.6 & 1.0 & 5.2 & 3.1 & 3.9 \\
Environment & 19 & 50 & 1.1 & 4.7 & 1.3 & 5.7 & 0.7 & 3.5 \\
Other responses & 1033 & 278 & 58.2 & 26.1 & 60.9 & 13.6 & 53.9 & 36.3 \\
Tot. no. of responses & 1775 & 1066 & 100 & 100 & 1092 & 581 & 683 & 485 \\
\hline
\end{tabular}

It is also interesting to highlight the differences in respondents' marking of values as "important for the society" and/or "important for me personally", in relation to their understanding of, for example, democracy. On the one hand, the study has shown that none of the values mentioned is viewed purely as societal or individual. As one can see in the table 2 below marking for Respect, for e.g., is practically equal for these two categories in both cultures. On the other hand, there are values that distinctly tend to be viewed from a more individual (Family) /societal perspective (Social security). The latter one is interesting as for Russia misbalance towards societal perspective is bigger than in Sweden and some comments made by respondents were about the fact that "it would have been nice to have it, but we don't in this country, so I don't expect it". However, in Russian data there is also thrice the difference in mentioning Law-abidance as "for society", then "for me", which, actually, supposes, quite paradoxically, that people would prefer a law-abiding society, but do not directly apply it to themselves.

Please note that the percentages in the following table were calculated only from the total sum of the number of times these three categories were mentioned.

Table 2 Value nominations divided into reflection on personal and/or societal importance. Percent. Russia $n=256$, Sweden $n=232$

\begin{tabular}{lllll} 
& \multicolumn{3}{c}{ Russia } & \multicolumn{3}{c}{ Sweden } \\
\cline { 2 - 5 } Value nomination & For me & For society & For me & For society \\
\hline Family & 41.0 & 20.3 & 32.8 & 8.6 \\
Respect & 13.3 & 12.5 & 10.3 & 11.2 \\
Care for citizens, social security & 4.3 & 8.6 & 16.4 & 20.1 \\
\hline
\end{tabular}


The second phase of the study highlighted interesting differences among the respondents regarding their attitudes to different value concepts. For example, the components of such concept as Democracy are not only neutral or having positive connotations (e.g. freedom of speech, equality) in Russian culture, but also there is a number of negative associations: power of crowd, lie, betrayal, disorder, instability, everything is allowed and humiliation. We believe that such answers reveal a reaction in part of the society to painful reforms of the 1990s. There were also associations like: The thing that we failed to build in our country, which may display disappointment in the course of reforms. Democracy was, by Swedish respondents, only positively understood as right to vote, responsiveness, all people are equal and similar descriptions.

The results of the second phase were used for composing a list for the ranking experiment where we planned to include only simple values that are understood similarly in the two cultures (according to our discussion in the Russian-Swedish research group), as complex ones are incomparable directly through ranking. 31 (of the most frequently mentioned in the first phase of the study and as components of complex values) simple values were included in this list.

The idea of ranking experiment in the third phase of the study was to find out the degree of importance of each value within the list of the 31 values presented to the respondents. For the analysis of the value ranking we worked with two types of data; the absolute place on the scale from 1 to 31 , and the means of the values indicating their relevance. Presented together in the table they indicate tendencies in placements. To exemplify we display some of the results for both men and women together:

Table 3 Ranking results for Russian respondents (both genders)

\begin{tabular}{lll} 
Absolute placement & Value nomination & $\begin{array}{l}\text { Relevant } \\
\text { placement (mean) }\end{array}$ \\
\hline 1. & Love & 7.25 \\
2. & Health & 7.85 \\
3. & Friendship & 8.57 \\
4. & Family and children & 8.71 \\
5. & Personal development & 10.00 \\
\hline 29. & Gender equality & 23.49 \\
30. & Love for one's country & 23.50 \\
31. & Democracy & 27.55 \\
\hline
\end{tabular}

Table 4 Ranking results for Swedish respondents (both genders) 


\begin{tabular}{lll} 
Absolute placement & Value nomination & $\begin{array}{l}\text { Relevant } \\
\text { placement (mean) }\end{array}$ \\
\hline 1. & Love & 5.64 \\
2. & Family & 7.51 \\
3. & Friendship & 8.19 \\
4. & Health & 9.62 \\
5. & mutual respect & 10.90 \\
\hline 29. & Culture and history, trad. & 24.08 \\
30. & Faith and religion & 26.99 \\
31. & Love for one's country & 27.60 \\
\hline
\end{tabular}

In table 1 we displayed the most frequently mentioned values. The comparison between table 1 and table 3 shows that for instance Material wealth has changed its position as the leading value to an absolute position of number 12 in Russia (mean value $=14.8$ ) and number 28 (mean value $=23.3$ ) in Sweden in the results of the ranking displayed in table 3. On the other hand, Love, being one of the fewest mentioned values nominations for Swedish respondents in table one, now top the list of ranking values in table 4. One possible way to interpret these results is that the leading position of Material wealth in the first phase may be explained by that it represents a big cluster of reactions, while intangible values are divided by the respondents into a larger number of specific categories. If these categories, as in the case of Material wealth, had been clustered together, it is possible that they could have outweighed material values in mentioning frequency. The top ranking values are very much alike in Sweden and Russia. However, this is not the case for the lowest ranking values.

The values that were least frequently mentioned in the first phase, displayed in table one (in some of the cases incorporated, due to limitations of this articles length, into the category Other responses), retained their low positions in the ranking. This consistency proves that they do play the least important role. In addition, we may note that the in the ranking experiment values found at the top of the list are all personal values.

As presented earlier in the article we applied the theory of graded representation to estimate the index of similarity/difference. A high index of similarity was obtained, for example, for Love $(\mathrm{Ks}=0.712)$ and Mutual help $(\mathrm{Ks}=0.712)$, whereas there is a low one for Material wealth (Ks 0.419), Gender equality, women's rights $(\mathrm{Ks}=0.439)$ and Democracy $(\mathrm{Ks}=0471)$. The concepts below are listed according to decreasing similarity index between the two cultures. 
Table 5 Index of similarity/difference between Russia and Sweden

\begin{tabular}{ll} 
Value & Ks \\
\hline Unity, solidarity, agreement & 0.723 \\
Love & 0.712 \\
Mutual help, support & 0.712 \\
Friendship & 0.708 \\
Environment & 0.691 \\
Leisure, entertainment & 0.691 \\
Job & 0.681 \\
Family and children & 0.670 \\
Patience & 0.663 \\
Health & 0.659 \\
Culture, history & 0.642 \\
Tranquility, calmness, peace of mind & 0.639 \\
Justice & 0.639 \\
Patriotism & 0.639 \\
Honesty & 0.635 \\
Social security (provided by the state) & 0.618 \\
Open-mindedness, readiness to accept others & 0.618 \\
Consideration, compassion, sympathy & 0.611 \\
Fatih and religion & 0.607 \\
Education & 0.597 \\
Politeness & 0.586 \\
Faithfulness, loyalty & 0.586 \\
Peace & 0.576 \\
Eelf-sufficency, independency & 0.576 \\
Mutual Respect & 0.576 \\
Human rights & 0.565 \\
\hline
\end{tabular}




\begin{tabular}{ll} 
Democracy & 0.471 \\
Gender equality & 0.439 \\
Material Wealth & 0.419 \\
\hline
\end{tabular}

As shown in table 5 above there are still differences between the respondents in the two countries. Not in terms of interpersonal values, they are to a high degree equally viewed as important, but in terms of how collective values (related to society/state/institutions) are ranked. Democracy and Gender equality are two collective values where differences are profound.

\section{Concluding remarks}

The analysis of the obtained experimental material shows adequacy of the methodology chosen. The first phase of the study allowed us to select such value nominations which are actual and significant for the respondents of the both nationalities. The following phases of the study allowed us to understand that the value system of the Swedish and Russian societies taken, as an example, can be presented as a sum of value concepts organized by as minimum two structures:

- $\quad$ Hierarchy organized according to the degree of value being more/less abstract-concrete (for example: "Democracy - Elections")

- Linear graded structure that fixes relative importance (positive/negative) of each value nomination within the system.

Our analysis also showed that the methodology that was worked out makes it possible to evaluate the degree of similarity or difference between Russian and Swedish value concepts which in dictionaries may be considered as equivalents.

As stated in the beginning of this article, Russia has during the last two decades experienced a societal transformation from a totalitarian society towards democracy with a novel value system in development. Sweden, on the other hand, has a history of a 'third way' (the Swedish model), in terms of over time relative stable societal values, democracy and mixed economy. This makes comparisons on value systems between the two countries interesting, as we have shown in this article. In coming articles we will elaborate further on these results, especially on the topic of democracy and gender equality. 


\section{Notes}

1 R Williams, Change and Stability in Values and Value Systems: A Sociological Perspective, in M Rokeach Understanding human values, Simon and Schuster, 2000, pp. 16, 20-21, 23.

${ }^{2}$ S Schwartz, W Bilsky 'Toward a Universal Psychological Structure of Human Values'. Journal of Personality and Social Psychology, vol. 53 (3), September 1987, pp.550-582.

${ }^{3}$ M Rokeach The Nature of Human Values, New York, The Free Press, 1973.

${ }^{4} \mathrm{G}$ Almond et al, Comparative Politics Today. A world view, Pearson, 2010, 9th Ed, p 377.

${ }^{5}$ D Hancock Politics in Europe. An Introduction to the Politics of the United Kingdom, France, German, Italy, Sweden, Russia, Poland and the European Union, Sage Publications Inc., 2006

${ }^{6}$ G Murphy 'Comprehending Complex Concepts'. Cognitive Science, vol. 12, issue 4, October-November 1988, pp. 529-582.

${ }^{7}$ V Shabes Event and Text, Moscow, Vysshaya Shkola, 1989, pp. 24-32.

${ }^{8}$ H J Zimmerman Fuzzy Set Theory and Its Applications, Kluwer Academic Publishers 2001 Fourth Ed.

${ }^{9}$ T Sørensen 'A Method of Establishing Groups of Equal Amplitude in Plant Sociology Based on Similarity of Species and Its Application to Analyses of the Vegetation on Danish Commons'. Biologiske Skrifter / Kongelige Danske Videnskabernes Selskab, 5 (4), 1957, pp. 1-34.

\section{Bibliography}

Almond, G. et al, Comparative Politics Today. A world view. Pearson, 2010, 9th Ed.

Hancock, D., Politics in Europe. An Introduction to the Politics of the United Kingdom, France, German, Italy, Sweden, Russia, Poland and the European Union. Sage Publications Inc., 2006.

Murphy, G., 'Comprehending Complex Concepts'. Cognitive Science, vol. 12, issue 4, October-November 1988, p. 529-582.

Rokeach, M., The Nature of Human Values, New York, The Free Press, 1973. 
Schwartz, S., Bilsky, W., 'Toward a Universal Psychological Structure of Human Values'. Journal of Personality and Social Psychology, vol. 53 (3), September 1987, pp. 550-582.

Shabes,V.J. Event and Text. Moscow, Vysshaya Shkola, 1989

Sørensen, T., 'A Method of Establishing Groups of Equal Amplitude in Plant Sociology Based on Similarity of Species and Its Application to Analyses of the Vegetation on Danish Commons'. Biologiske Skrifter / Kongelige Danske Videnskabernes Selskab, 5 (4), 1957, pp. 1-34.

Williams, R., 'Change and Stability in Values and Value Systems: A Sociological Perspective", in Rokeach, M., Understanding Human Values, Simon and Schuster, 2000. pp. 15-46

Zimmerman, H.J., Fuzzy Set Theory and Its Applications. Kluwer Academic Publishers, 2001 Fourth Ed.

Vladimir Shabes is Doctor of Linguistics, Full Professor at the Department of Romanic Languages, Herzen State Pedagogical University, Russia. His main academic interests lie in the theory of mental representation and experimental cognitive linguistics.

Göran Bostedt is Associate Professor of Political Science at the Department of Education, Mid-Sweden University. His main areas of research are currently on how to understand local governance, student influence in schools and social science didactics.

Ekaterina Troshchenkova is Associate Professor at the Department of English, St.-Petersburg State University. Her interests are in cognitive science and psycholinguistics, especially sociocultural mental representations and communicative strategies of manipulation and metarepresentation.

Lena Ivarsson, PhD, Assistance Professor in Education at the Department of Education, Mid Sweden Uiversity, Sweden. She is interested in learning processes, reading and writing development, and international co-operation.

Ulla Damber is Senior Lecturer in pedagogy and a teacher educator at Mid Sweden University. Her main research area is literacy, including didactics and diversity.

Tamara Potapova is Senior Lecturer at the Department of English for Economy and Law students, St.-Petersburg State University. While being 
interested mainly in psycholinguistic research of graded lexical paradigms and problems of understanding within and between genders, the current research where she participates together with colleagues is devoted to analysis of special features of value systems of Russians and Swedes and their comparative analysis. 